\title{
FEATURES OF THE SEMANTIC-SYNTACTIC PROCESS OF ADVERBIALISATION IN MODERN COLLOQUIAL SPEECH
}

\author{
Anna V. Degaltseva \\ Saratov National Research State University named after N.G. Chernyshevsky, Saratov, Russia
}

\begin{abstract}
The study of semantic-syntactic compression is an urgent linguistic problem. One of the processes that lead to the statement meaning complication is adverbialisation, the essence of which is that the adverb, which is grammatically dependent on the verb, semantically refers to the statement or one of its basic proposition components. This work is carried out in line with semantic syntax and is devoted to studying the adverbial complicator functioning (adverbs that complicate the semantic structure of the sentence) in modern colloquial speech. Native speakers use these language units to add event propositions, logical propositions of characterization or comparison to a statement, to characterize the actants of basic propositions and to express the confidence category or the statement objective content evaluation as well. The adverbial complicators which can be transformed into social actions, emotional or mental states of a subject prevail in colloquial speech. Adverbs-complicators are used most frequently with the verbs of speech and intellectual activity expressing the emotional or mental state of a person. Adverbs that involve logical propositions are usually used to describe a person's behavior or character. Such language units, which are used to evaluate the objective content of a statement, prevail among the adverbs expressing modus categories.

Key words: adverbialisation, adverb, semantic syntax, syntactic compression, adverbial complicator, colloquial speech, Russian language.

Citation. Degaltseva A.V. Features of the Semantic-Syntactic Process of Adverbialisation in Modern Colloquial Speech. Vestnik Volgogradskogo gosudarstvennogo universiteta. Seriya 2, Yazykoznanie [Science Journal of Volgograd State University. Linguistics], 2019, vol. 18, no. 1, pp. 113-121. (in Russian). DOI: https://doi.org/ 10.15688/jvolsu2.2019.1.9
\end{abstract}

УДК 811.161 .1 '242

Дата поступления статьи: 25.07.2018

ББК $81.411 .2-55$

Дата принятия статьи: 18.03.2019

\section{СЕМАНТИКО-СИНТАКСИЧЕСКАЯ АДВЕРБИАЛИЗАЦИЯ В СОВРЕМЕННОЙ РАЗГОВОРНОЙ РЕЧИ}

\author{
Анна Владимировна Дегальцева \\ Саратовский национальный исследовательский государственный университет им. Н.Г. Чернышевского, \\ г. Саратов, Россия
}

\footnotetext{
Аннотация. В статье рассматривается актуальная лингвистическая проблема выявления способов семантико-синтаксической компрессии. Анализируется один из процессов, приводящих к усложнению смысла высказывания, - адвербиализация, суть которой заключается в том, что наречие, грамматически связан궁 ное с глаголом, семантически соотносится со всем высказыванием или одним из компонентов его базовой ๓ пропозиции. Работа выполнена в русле семантического синтаксиса и посвящена изучению функционирования адвербиальных компликаторов (наречий, усложняющих семантическую структуру предложения) в со\% жания высказывания, выражение модусной категории персуазивности. 
состояния. Чаще всего наречия-компликаторы употребляются при глаголах речевой и интеллектуальной деятельности, называя эмоциональное или ментальное состояние субъекта. Наречия, которые заключают в себе логические пропозиции, обычно используются для описания поведения или черт характера человека. Среди наречий-компликаторов, выражающих модусные категории, преобладают синтаксемы, которые служат для оценки объективного содержания высказывания.

Ключевые слова: адвербиализация, наречие, семантический синтаксис, синтаксическая компрессия, адвербиальный компликатор, разговорная речь, русский язык.

Цитирование. Дегальцева А. В. Семантико-синтаксическая адвербиализация в современной разговорной речи // Вестник Волгоградского государственного университета. Серия 2, Языкознание. - 2019. - Т. 18, № 1. - C. 113-121. - DOI: https://doi.org/10.15688/jvolsu2.2019.1.9

\section{Изучение разговорной речи в современной лингвистике}

Изучение устной речи получило начало еще в трудах В. фон Гумбольдта, писавшего о необходимости пристального внимания к живой разговорной речи [Гумбольдт, 2013] и Л.П. Якубинского, исследовавшего диалогическую речь [Якубинский, 1986]. Наибольший интерес к разговорной речи (далее - РР) проявился в лингвистической науке во второй половине XX века.

Несмотря на значительное количество работ, посвященных изучению РР, в современной коммуникативистике до сих пор не существует единого взгляда на это понятие. Некоторые лингвисты рассматривают РР как разновидность или тип национального русского языка, другие - как функциональный стиль литературного языка.

В современной лингвистике сформировалось несколько речеведческих концепций, связанных с именами Е.А. Земской, О.А. Лаптевой, О.Б. Сиротининой, В.В. Химика и других. Представители Московской лингвистической школы речеведения - Е.А. Земская, М.В. Китайгородская, Е.Н. Ширяев - понимают РР как «особую языковую систему, противопоставленную в пределах литературного языка кодифицированному литературному языку» [Земская, Китайгородская, Ширяев, 1981, c. 5]. Согласно такому пониманию, РP - это «особый литературный язык». Другой представитель Московской лингвистической школы - О.А. Лаптева - предлагает выделять устно-разговорную разновидность современного русского языка, которая не ограничивается принадлежностью к какому-то определенному функциональному стилю. К этой разновидности языка относятся обиходно-быто- вое, служебное общение и даже устные публичные выступления [Лаптева, 1976]. Довольно широко понимает РР и белгородский лингвист В.К. Харченко. В рамках РР она рассматривает бытовые разговоры, научные и деловые беседы и т. д. [Харченко, 2010]. Таким образом, в концепциях О.А. Лаптевой и В.К. Харченко одним из ведущих параметров РР является устность.

Понимание РР в рамках Саратовской лингвистической школы сформировалось и наиболее полно отражается в трудах О.Б. Сиротининой. Ученый рассматривает РР в качестве разновидности русского литературного языка: как его отдельную коммуникативную систему со своими нормами. РР чаще всего реализуется в устном неофициальном общении [Сиротинина, 1993].

Согласно концепции В.В. Химика, представителя Санкт-Петербургской филологической школы, РР - устная спонтанная коммуникация, в которой могут использоваться разнообразные лексические средства: от нейтральных до нелитературных и даже обсценных [Химик, 2015].

В данной работе мы, вслед за О.Б. Сиротининой, будем понимать под РР обиходную разновидность русского литературного языка, которая реализуется в непубличном неофициальном общении и существует как в устной (преимущественно), так и в письменной формах. Устная форма представлена непосредственным живым общением, а письменная - опосредованной коммуникацией (дневниковыми записями, записками, неофициальными письмами, беседами в социальных сетях, блогами и видеоблогами, смс-сообщениями, чатами и другими речевыми жанрами [Литневская, 2011]).

Основной для РР является функция общения, а доминантой - «минимум заботы о 
форме выражения» [Сиротинина, 1993, с. 137]. РP характеризуется устностью, неофициальностью, непосредственностью, спонтанностью, ситуативностью, персональностью и политематичностью общения [Земская, Китайгородская, Ширяев, 1981]. Эти черты обиходно-бытовой речи влекут за собой нечеткость произношения, неточность или небрежность в выборе слов, а также употребление слов-«губок» (диффузов) с широкой или неопределенной семантикой, использование преимущественно простых предложений, размытость границ высказывания, применение средств экономной передачи информации: прежде всего, лексической и семантико-синтаксической компрессии [Земская, Китайгородская, Ширяев, 1981, с. 82; Сиротинина, 1993]. Далее рассмотрим особенности функционирования в PP наречий, усложняющих смысл высказывания и приводящих к экономии речевых усилий говорящего или пишущего. Прежде чем обратиться к характеристике методов и материала исследования, определим статус таких единиц в системе русского языка.

\section{Статус наречий-компликаторов в синтаксической системе русского языка}

Изучение средств семантико-синтаксической компрессии является одним из актуальных и перспективных направлений современных лингвистических исследований. В роли усложнителей семантической структуры предложения выступают отглагольные существительные, инфинитивы, причастия, деепричастия и т. д. [Кормилицына, 2011]. В русском языке также существуют наречия с пропозициональной семантикой: находясь в грамматической зависимости от глагола, они характеризуют один из компонентов базовой пропозиции или оценивают все диктумное содержание высказывания. Подобные адвербиальные лексемы в англоязычной научной литературе принято называть «sentence adverbials» или «sentence modifiers» [Greenbaum, 1969; Maienborn, Schäfer, 2011], в русской - сентенциальными наречиями [Рудницкая, 1994], атрибутивно-обстоятельственными компликаторами [Кормилицына, 2011], наречиями-детерминантами [Рудницкая, 1994], обстоятельства- ми образа действия с пропозитивной семантикой [Хорук, 2008]. Мы, вслед за Г.А. Золотовой, будем использовать термин «адвербиальные компликаторы» (далее - АК) - усложнители элементарных моделей предложений [Золотова, 1982, с. 167]. Процесс семантического осложнения предложения путем введения в него наречия или деепричастия в трудах Г.А. Золотовой получил название «адвербиализация» [Золотова, 1982]. В современной лингвистической науке не так много работ, посвященных специальному изучению этого семантико-синтаксического процесса [Дегальцева, 2017; Рудницкая, 1994; Хорук, 2008], чем и объясняется актуальность выбранной темы исследования.

\section{Материал и методы исследования}

Устная форма РР изучается нами на материале данных, представленных в подкорпусе устной речи Национального корпуса русского языка (НКРЯ), а также на основе авторских расшифровок видеоблогов различной тематики на платформе Youtube (Юв). Письменная форма РР анализируется на материале сетевых дневников, размещенных на сервисе «Живой Журнал» (ЖЖ), записей бесед на форумах (Ф), комментариев под видео разнообразной тематики, представленных на видеохостинге Youtube (Юк). Выбранные жанры отражают разную степень подготовленности высказываний. Так, блоги нередко являются стилистически разнородными: могут сочетать черты РР и публицистики, художественной прозы или делового общения [Интернет-коммуникация..., 2012; Литневская, 2011]. Для исследования мы отобрали частные некоммерческие блоги, в которых отсутствует социально-политическая тематика и ощущается высокая степень спонтанности порождения языковых единиц. В приводимых в статье контекстах авторские орфография и пунктуация сохранены.

Общий объем собранного материала составил 20000 предикативных единиц, из которых были выделены 257 АК. При сборе и исследовании фактов использовались следующие приемы и методы: сплошной выборки, интерпретативный, логико-синтаксический, контекстуального и компонентного анализа. 


\section{РАЗВИТИЕ И ФУНКЦИОНИРОВАНИЕ РУССКОГО ЯЗЫКА}

\section{Функции наречий-компликаторов в РP}

В обиходно-бытовой речи, согласно нашим данным, лишь 14 из 1000 предикативных единиц осложнены путем адвербиализации. Это связано с тем, что в РР (особенно в устной ее форме) наречия распространены не так широко, как в некоторых других сферах общения, поскольку «визуально-чувственная ситуация, в которой оказываются участники разговора, резко снижает потребность говорящих в выражении качественной характеристики действия» [Ножкина, 2008, с. 126]. Кроме того, незначительную представленность наречий в РP можно объяснить такими ее особенностями, как спонтанность порождения высказываний, сведение к минимуму заботы о форме выражения мысли, шаблонность фраз, почти полное отсутствие образности, преобладание лексем с конкретной семантикой [Земская, Китайгородская, Ширяев, 1981].

В устной форме РР в силу ее спонтанности, автоматизма, стремления «к использованию готовых единиц» [Земская, Китайгородская, Ширяев, 1981 , с. 6] стандартизованность преобладает над образностью. Это находит отражение и в функционировании наречий-компликаторов. В устной речи индекс лексического разнообразия АК составляет 0.2 , что в два раза ниже, чем в письменной. Здесь обычно встречаются наречия-компликаторы, которые приобретают стереотипность в результате частого употребления в разных ситуациях бытового общения (бесплатно, вкусно, серьезно, спокойно, честно и др.):

(1) Варила вкусно она// (НКРЯ). (НКРЯ).

(2) Погорельцам бесплатно лес давали//

(3) Я провела этот эфир/ но я вам честно скажу/ я верю в то/ что он пойдет на пользу// (Юв).

АК, употребляющиеся в письменной форме $\mathrm{PP}$, могут обладать большей образностью и экспрессивностью. Это объясняется тем, что у пишущего, в отличие от говорящего, есть некоторое время на обдумывание текста своего сообщения:

(4) Но здесь восторженно аплодирую! (ЖЖ).

(5) Хотя я показательно вежлива и внимательна к людям, пусть и закрыта, но со мной никто не связывается, всегда держат дистанцию (Юк).
Несмотря на шаблонность и стандартизованность РР, в ней может реализоваться и творческое отношение к слову [Земская, Китайгородская, Ширяев, 1981, с. 183-188; Харченко, 2010]. Однако, как отмечает В.К. Харченко, талант носителей языка к повседневному словотворчеству редок и почти уникален [Харченко, 2010]. Приведем некоторые примеры:

(6) Засилье розового - такого розового, жвачно розового, искусственного - нездорово (ЖЖ).

(7) «День сурка» по-геймерски (Юк).

(8) Топ-модель по-ютубоски!!! (Юк).

(9) Кто захочет обзавестись в Омске моей литературой, свяжитесь с Аней интернетно (ЖЖ).

Окказиональные АК чаще всего образуются от заимствованных слов - примеры (7-9), это легко объясняется тем, что «основу лексики интернет-коммуникации составляют кальки и прямые заимствования из английского языка» [Осетрова, 2018, с. 160].

Согласно проведенному исследованию, наречия-компликаторы в изучаемой сфере коммуникации выполняют 2 основные функции: вводят в высказывание побочные пропозиции (событийные и логические) или выражают модусные категории. Обратимся к рассмотрению каждой из функций данных наречий.

Подавляющее большинство АК в РР (234 употребления АК, 91 \%) вводит в высказывание дополнительную пропозицию, отражая объективное содержание положения дел в действительности, то есть диктумный план высказывания. При этом 69 \% АК (162 из 234 употреблений) содержат в себе свернутые событийные пропозиции и используются для введения в предложение различных ситуаций. Это помогает говорящему или пишущему наиболее емко выразить мысль, не затрачивая большого количества языковых средств. Например:

(10) Сервис не берет денег, читать бесплатно можно абсолютно все $(\Phi)$.

В высказывании (10) АК разворачивается в пропозицию социального действия: не нужно платить денег.

Около $40 \%$ из 162 употреблений наречий-компликаторов, заключающих в себе в 
свернутом виде событийные пропозиции, называют социальные действия:

(11) Пять способов ездить по выделенке безнаказанно (ЖЖ).

(12) Ну как/ платные палаты тоже есть/ но от того/ что ты будешь платно рожать/ там.../ ничего...// (НКРЯ).

Использование наречий-компликаторов, называющих такие действия, по-видимому, обусловлено тематикой общения.

Адвербиальные компликаторы часто необходимы для более полной и убедительной передачи эмоционального и эмоционально-ментального состояния субъекта (на них приходится $29 \%$ из 162 употреблений АК). Использование таких синтаксем можно объяснить стремлением адресанта охарактеризовать чувства и эмоции (свои, собеседников или людей, не принимающих участия в разговоре) и передать информацию живо, наглядно, а также придать беседе более открытую, доверительную тональность: (НКРЯ).

(13) Он так смотрит на нее удивленно...// (НКРЯ).

(14) < ...> Смотрю/ значит/ спокойно на него//

Примерно 21 \% из 162 употреблений АК служит для характеристики ментального состояния человека. Такие наречия-компликаторы используются говорящими или пишущими для поддержания обратной связи с собеседником. Адресант таким образом выражает свой интерес к теме разговора, проявляет внимание к адресату или подтверждает, что видит его заинтересованность в беседе. Подобные АК обычно отмечаются при глаголах речевого действия или психического восприятия:

(15) Так рассказала ты все интересно и по делу! (Юк).

(16) Вы так слушали меня внимательно// (НКРЯ).

Около 7 \% из 162 употреблений АК используется для характеристики физического состояния человека:

(17) От мала до велика народ толстый, реально нездорово толстый, особенно подростки (ЖЖ).
(18) Толпа низкооплачиваемых клерков вяло перекладывает пару бумажек из папки в папку (Ф).

Наречия, которые заключают в себе другие типы событийных пропозиций, представлены в РР незначительно.

Наречия-компликаторы, которые содержат логические пропозиции, составляют $31 \%$ АК (72 из 234 употреблений), реализуют диктумный план высказывания. Такие наречия могут описывать качества и свойства актантов (субъекта или эксплицитно не выраженного объекта) базовой пропозиции, а также вводить в высказывание дополнительную пропозицию со значением сравнения или подобия. Большинство из них (73\% из 72 АК) используется для передачи особенностей поведения и характера человека, не принимающего участия в разговоре. Такие АК позволяют говорящему или пишущему эмоционально оценить манеры окружающих:

(19) Нагло заявили/ говорят/ мы хоть два года у тебя жить будем// (НКРЯ).

(20) Полицейские нахально и непрерывно нарушают (Юк).

На АК, которые могут употребляться для оценочной характеристики объекта как имплицитного компонента пропозиции, приходится около $19 \%$ из 72 наречий, заключающих в себе в свернутом виде логические пропозиции. Например:

(21) Кормили на убой/ очень вкусно// Сытно кормили// (НКРЯ).

АК, содержащие релятивную логическую пропозицию со значением сравнения, уподобления (в концепции Т.В. Шмелевой - пропозицию подобия [Шмелева, 1994]), составляют около $6 \%$. Они образуются с помощью широко распространенных в РР конфиксов по-...-ому, nо-...-ему, по-...-и [Земская, Китайгородская, Ширяев, 1981]. Например:

(22) У каждой матери своя иконка/ и каждая мать благословляет пару по-своему// (НКРЯ).

В этом высказывании наречие выражает значение «так, как свойственно именно ей». Эти 
АК могут употребляться присубстантивно, характеризуя особенности приготовления различных блюд или напитков:

(23) «Готовим кофе по-венски или Кон Панна».

Видеоблогер, так назвавший свой контент (Юк), сообщает зрителю, что будет делать напиток из эспрессо с добавлением сливок и caxapa.

Лишь $2 \%$ из 72 употреблений наречий, которые содержат в себе свернутые логические пропозиции, служат для характеристики внешнего вида человека или животного:

(24) Женщины обладают волшебным даром материализовать прям из воздуха еще пару-тройку каких-то баб, которые сисясто над тобой нависнут (ЖЖ). ков! (Юв)

(25) Представляю топ 5 пушисто милых коша-

Это связано с тем, что наречия, в отличие от прилагательных и причастий, не являются типичными средствами описания внешности субъекта.

Рассмотрим подробнее вторую функцию наречий-компликаторов. АК, выражающие модусные категории, составляют только $9 \%$ (23 контекста) от всех 257 проанализированных контекстов, поскольку употребление наречий не является специализированным способом выражения модусных смыслов. Обычно такие наречия служат для оценки ситуаций или фактов (99 \% из 23 контекстов), отраженных в диктуме высказывания, что связано с аксиологическим характером PР, ее субъективностью и экспрессивностью. Например:

(26) За это платят/ что нас когда-то депортировали несправедливо// (НКРЯ).

В приведенном высказывании наречие-компликатор помогает говорящему оценить принудительное выселение как несправедливое, неправильное действие. Среди оценок, которые выражаются изучаемыми наречиями, преобладают нормативные. Адресанту, употребляющему такие оценочные АК, важно не просто выразить согласие с собеседником, но и соотнести факты и явления, о которых идет речь, с собственным представлением о норме и правильности:

(27) Да, есть такое, ты правильно подметил))(Ф).

Незначительное количество АК (менее $1 \%$ из 23 контекстов) служит для выражения модусной категории персуазивности, позволяя говорящему высказать уверенность или сомнение в передаваемой им информации:

(28) Блин/ не люблю говорить уверенно/ вдруг не получится// (НКРЯ).

(29) В шесть мы уже точно будем в метро и доедем до Павелецкой// (НКРЯ).

\section{Адвербиальные компликаторы и лексическая семантика предиката}

Поскольку наречие-компликатор грамматически зависит от глагола-сказуемого, существует зависимость употребления АК от семантики предикатов базовых пропозиций. Наиболее часто они используются при словах, входящих в самое многочисленное в языке лексико-семантическое поле «Действие и деятельность». В большинстве случаев АК употребляются при глаголах речевой, интеллектуальной, социальной и физической деятельности. Данные глаголы составляют 26, 19, 14 и 12 \% от всех 257 глаголов-предикатов соответственно. Частое употребление наречий-компликаторов при глаголах речевой и интеллектуальной деятельности, по-видимому, объясняется тем, что в русском языке многие глагольные лексемы не обладают способностью уточнять, детализировать характер такой деятельности. Эта особенность наречий-усложнителей была отмечена и в исследовании М.А. Кормилицыной, рассматривавшей атрибутивно-обстоятельственные компликаторы в устной речи [Кормилицына, 2011]. АК при таких глаголах способны называть ментальное или эмоциональное состояние субъекта во время чтения и письма, говорения и слушания, оценочно характеризовать объект восприятия или речевого сообщения. Частое употребление АК при глаголах социальной и физической деятельности, по-видимому, объясняется тематикой исследуемого материала: обсуждением бытовых или социальных явлений и процессов. 


\section{Выводы}

Наречия-компликаторы используются коммуникантами в качестве средства экономной передачи информации, реже - в роли способа создания выразительности высказывания.

В большинстве случаев АК в РР употребляются для введения в высказывание побочной событийной пропозиции (социального действия, эмоционального и ментального состояния). Кроме того, наречия используются говорящими или пишущими для характеристики актантов базовых пропозиций, введения в высказывание логической пропозиции уподобления или сравнения, оценки диктумного содержания высказывания или выражения модусной категории персуазивности.

Наречия-компликаторы чаще всего употребляются при глаголах речевой и интеллектуальной деятельности, называя эмоциональное и ментальное состояние субъекта действия или оценочно характеризуя объект пропозиции.

\section{СПИСОК ЛИТЕРАТУРЫ}

Гумбольдт В. фон, 2013. О различии организмов человеческого языка и о влиянии этого различия на умственное развитие человеческого рода: Введение во всеобщее языкознание. 2-е изд. M. : URSS. 376 c.

Дегальцева А. В., 2017. К вопросу о статусе адвербиальных компликаторов в синтаксической системе русского языка // Филология и человек. № 2. С. 104-111.

Земская Е. А., Китайгородская М. В., Ширяев Е. Н., 1981. Русская разговорная речь. Общие вопросы. Словообразование. Синтаксис. М. : Наука. 276 c.

Золотова Г. А., 1982. Коммуникативные аспекты русского синтаксиса. М. : Наука. 368 с.

Интернет-коммуникация как новая речевая формация, 2012 / науч. ред. Т. Н. Колокольцева, О. В. Луговинова. М. : ФЛИНТА: Наука. 328 с.

Кормилицына М. А., 2011. Семантически осложненное (полипропозитивное) простое предложение в устной речи. 3-е изд. М. : ЛИБРОКОМ. $152 \mathrm{c}$.

Лаптева О. А., 1976. Русский разговорный синтаксис. М. : Наука. 396 с.

Литневская Е. И., 2011. Письменные формы русской разговорной речи (к постановке проблемы). М. : МАКС Пресс. 304 с.
Ножкина Э. М., 2008. Наречие // Разговорная речь в системе функциональных стилей современного русского литературного языка. Грамматика / под ред. О. Б. Сиротининой. М. : ЛИБРОКОМ. С. 124-149.

Осетрова О. И., 2018. Заимствования в интернеткоммуникации: проблема орфографической вариативности и ее отражение в словарях // Филологические науки. Вопросы теории и практики. № 3 (81), ч. 1. С. 160-163.

Рудницкая Е. Л., 1994. Некоторые классы сентенциальных наречий в русском языке. Семантика. Синтаксис. Лексикография. Текст // Вопросы языкознания. № 1. С. 114-125.

Сиротинина О. Б., 1993. Разговорная речь // Функциональные стили и формы речи / под ред. О. Б. Сиротининой. Саратов : Изд-во Сарат. ун-та. С. 137-148.

Харченко В. К., 2010. Современная повседневная речь. 2-е изд. М. : ЛКИ. 184 с.

Химик В. В., 2015. Русская разговорная речь: общее понятие, обучение и вопросы терминологии // XLIII Международная филологическая конференция (СПб., 11-16 марта 2014 г.): Избранные труды / под ред. А. В. Бабанова [и др.]. СПб. : Изд-во СПбГУ. С. 460-471.

Хорук К. М., 2008. Обстоятельства образа действия как средство усложнения семантики предложения // Материалы XLVI Международной научной студенческой конференции «Студент и научно-технический прогресс»: Языкознание. Новосибирск : НГУ. С. 87-88.

Шмелева Т. В., 1994. Семантический синтаксис. Текст лекций. Красноярск : Изд-во Краснояр. гос. ун-та. 43 c.

Якубинский Л. П., 1986. Избранные работы: Язык и его функционирование. М. : Наука. 206 с.

Greenbaum S., 1969. Studies in English Adverbial Usage. Coral Gables, Univ. of Miami Press Publ. $262 \mathrm{p}$.

Maienborn C., Schäfer M., 2011. Adverbs and adverbials // Semantics: an international handbook of natural language meaning / C. Maienborn [et al.] (eds.). Berlin; New York : de Gruyter Mouton Publ. Vol. 2. P. 1390-1420. (HSK Handbook series).

\section{ИСТОчникИ}

ЖЖ - дневники на сайте «Живого Журнала». URL: https://iar-elterrus.livejournal.com/ (дата обращения: 20.07.2018); URL: https:// a-krotov.livejournal.com/1136276.html (дата обращения: 20.07.2018); https://101. livejournal.com/7671388.html (дата обращения: 20.07.2018). 
НКРЯ - Национальный корпус русского языка. Устный подкорпус. URL: http://www.ruscorpora. $\mathrm{ru} /$ search-spoken.html.

$\Phi$

- данные форумов. URL: https://psycheforum. ru/forum 4.html (дата обращения: 10.06.2018); URL: http://www.aspirantura. spb.ru/forum/ (дата обращения: 10.06.2018).

Юв - расшифровки текстов видео на платформе Youtube. URL: https://www.youtube. com/watch?v=Wj892IHhNRk (дата обращения: 17.06.2018); URL: https://www. youtube.com/watch?v=iijEwWjg5Cw (дата обращения: 10.06.2018).

Юк - комментарии или текстовые описания к видеоконтенту на платформе Youtube. URL: https://www.youtube.com/watch?v= Wj892IHhNRk (дата обращения: 17.06.2018); URL: https://www.youtube.com/watch?v= mshYY-EKBPQ\&t =2s (дата обращения: 20.07.2018); URL: https://www.youtube.com/ watch?v=rxwA3YhboZw (дата обращения: 20.07.2018)

\section{REFERENCES}

Humboldt W. von, 2013. On Language: The Diversity of Human Language-Structure and Its Influence on the Mental Development of Mankind: Introduction to General linguistics. $2^{\text {nd }}$ ed. Moscow, URSS Publ. 376 p.

Degaltseva A.V., 2017. To the Question of the Status of Adverbial Complicators in the Syntactical System of the Russian Language. Filologiya $i$ chelovek, no. 2, pp. 104-111.

Zemskaya E.A., Kitaygorodskaya M.V., Shiryaev E.N., 1981. Russian Colloquial Speech. General Issue. Word-Formation. Syntax. Moscow, Nauka Publ. 276 p.

Zolotova G.A., 1982. Communicative Aspects of Russian Syntax. Moscow, Science Publ. 368 p.

Kolokoltseva T.N., Lutovinova O.V., eds. InternetCommunication as a New Speech Formation. Moscow, Flinta Publ, Nauka Publ. 328 p.

Kormilitsyna M.A., 2011. Semantically Complicated (Polipropositional) Simple Sentence in Spoken Speech. $3^{\text {rd }}$ ed. Moscow, LIBROKOM Publ. 152 p.

Lapteva O.A., 1976. Russian Spoken Syntax. Moscow, Nauka Publ. 206 p.

Litnevskaya E.I., 2011. The Written Forms of Russian Colloquial Speech (Problem Statement). Moscow, MAKS Press Publ. 304 p.

Nozhkina E.M., 2008. Adverb. Razgovornaya rech v sisteme funktsionalnykh stiley sovremennogo russkogo literaturnogo yazyka. Grammatika [Colloquial Speech in the System of Functional
Styles of the Modern Russian Literary Language. Grammar]. Moscow, LIBROKOMPubl,pp. 124-149.

Osetrova O.I., 2018. Loan Words of Internet Communication: the Problem of Spelling Variability and Its Representation in Dictionaries. Filologicheskie nauki. Voprosy teorii i praktiki [Philological Sciences. Issues of Theory and Practice], no. 3 (81), part 1, pp. 160-163.

Rudnitskaya E.L., 1994. Nekotorye klassy sententsialnykh narechiy v russkom yazyke. Semantika. Sintaksis. Leksikografiya. Tekst [Some Classes of Sentential Adverbs in the Russian Language. Semantics. Syntax. Lexicography. Text]. Voprosy yazykoznaniya [Topics in the Study of Language], no. 1, pp. 114-125.

Sirotinina O.B., 1993. Colloquial Speech. Funktsionalnye stili i formy rechi [Functional Styles and Forms of Speech]. Saratov, Izd-vo Saratovskogo Universiteta, pp. 137-148. Kharchenko V.K., 2010. Modern Everyday Speech. $2^{\text {nd }}$ ed. Moscow, Izd-vo LKI. 184 p.

Khimik V.V., 2015. Russian Colloquial Speech: Its Concept, Teaching and Terminology. XLIII Mezhdunarodnaya filolologicheskaya konferentsiya (SPb., 11-16 marta 2014 g.): Izbrannye Trudy. Saint Petesburg, Izd-vo SPbGU, pp. 460-471.

Khoruk K.M., 2008. Circumstances of Way of Action as a Means of Complicating the Semantics of the Sentence. Materialy XLVI Mezhdunarodnoy nauchnoy studencheskoy konferentsii «Student i nauchno-tekhnicheskiy progress»: Yazykoznanie [Materials of the XLVI Intern. Scientific Student Sonference "Student and Scientific and Technological Progress": Linguistics]. Novosibirsk, NGU Publ., pp. 87-88.

Shmeleva T.V., 1994. Semantic Syntax. The Text of the Lectures. Krasnoyarsk, Izd-vo Krasnoyarskogo gosugarstvennogo universiteta. $43 \mathrm{p}$.

Yakubinskiy L.P., 1986. Selected Works: Language and Its Functioning. Moscow, Nauka Publ. 206 p.

Greenbaum S., 1969. Studies in English Adverbial Usage. Coral Gables, Univ. of Miami Press Publ. 262 p.

Maienborn C., Schäfer M., 2011. Adverbs and Adverbials. Semantics: An International Handbook of Natural Language Meaning. Berlin. New York, de Gruyter Mouton Publ., vol. 2. pp. 1390-1420. (HSK Handbook series).

\section{SOURCES}

Live Journal Blogs. URL: https://iar-elterrus.livejournal. com/ (Accessed 20 July 2018); https://a-krotov. livejournal.com/1136276.html (Accessed 20 July 2018); https://101.livejournal.com/7671388.html (Accessed 20 July 2018). 
A.В. Дегальщева. Семантико-синтаксическая адвербиализация в современной разговорной речи

Data of Spoken Subcorpus of Russian National Corpus. URL: http://www.ruscorpora.ru/searchspoken. html.

Data of Forums. URL: https://psycheforum.ru/forum4.html (Accessed 10 June 2018); URL: http://www. aspirantura.spb.ru/forum/ (Accessed 10 June 2018).

Verbatim Records of Youtube's Videos. URL: https:// www.youtube.com/watch? $\mathrm{v}=\mathrm{Wj} 892 \mathrm{IHhNRk}$ (Accessed 17 July 2018); https://www.youtube. com/watch? $\mathrm{v}=\mathrm{iijEwWjg} 5 \mathrm{Cw}$ (Accessed 10 June 2018).

Youtube's Video Comments and Descriptions. URL: https://www.youtube.com/watch?v= Wj892IHhNRk (Accessed 17 June 2018); URL: https://www.youtube.com/watch?v=mshYYEKBPQ\& $=2$ s (Accessed 20 July 2018); URL: https://www.youtube.com/watch?v= rxwA3YhboZw (Accessed 20 July 2018).

\section{Information about the Author}

Anna V. Degaltseva, Candidate of Sciences (Philology), Associate Professor, Department of the Russian Language, Speech Communication and Russian as a Foreign Language, Saratov National Research State University named after N.G. Chernyshevsky, Astrakhanskaya St., 83, 410012 Saratov, Russia, deganna@mail.ru,https://orcid.org/0000-0003-3791-9777

\section{Информация об авторе}

Анна Владимировна Дегальцева, кандидат филологических наук, доцент кафедры русского языка, речевой коммуникации и русского как иностранного, Саратовский национальный исследовательский государственный университет им. Н.Г. Чернышевского, ул. Астраханская, 83, 410012 г. Саратов, Россия, deganna@mail.ru, https://orcid.org/0000-0003-3791-9777 